\title{
The Inhibitory Effects of Tetracycline on Mastocytosis
}

\author{
Damilola Runsewe \\ Department of Chemical Engineering, Lamar University, Beaumont, TX, USA \\ Email: drunsewe@lamar.edu
}

How to cite this paper: Runsewe, D. (2019) The Inhibitory Effects of Tetracycline on Mastocytosis. Journal of Biosciences and Medicines, 7, 33-58.

https://doi.org/10.4236/jbm.2019.76004

Received: April 24, 2019

Accepted: June 2, 2019

Published: June 5, 2019

Copyright $\odot 2019$ by author(s) and Scientific Research Publishing Inc. This work is licensed under the Creative Commons Attribution International License (CC BY 4.0).

http://creativecommons.org/licenses/by/4.0/

\begin{abstract}
Mastocytosis is a rare disease that causes its victims pains in the body, anaphylactic shocks and in some cases death. There is currently no cure for this disease but there are some medications taken to manage the symptoms of this disease. The cause of mastocytosis is the overabundance of mast cells in the blood stream, body tissues, and bone marrow. These mast cells are well meaning hematopoietic cells which are members of the body's response to an allergy. It has been established that tetracyclines possess anti-bacterial properties, but recent development has also shown that it also possesses anti-inflammatory properties as well as apoptotic properties which can be applied in the treatment of mastocytosis. This paper focuses on the use of the principle of "Creative synthesis" to formulate a possible treatment to mastocytosis using tetracycline and polyphenols as well as chemically modified tetracyclines (CMTs). In addition, investigations will be carried out to proffer a possible combination which will help in inhibiting the effects of mastocytosis. Based on the synthesis, an economic analysis will be carried out to show the economic potential of this proffered treatment.
\end{abstract}

\section{Keywords}

Tetracycline, Chemically Modified Tetracycline, Mast Cells, Mastocytosis, Polyphenols

\section{Introduction}

As much as the cells perform a well-meaning agenda within the body by responding to foreign allergens, it is also reported to function in manners that lead from an annoying to catastrophic reactions and possibly contribute to the pathology of autoimmune diseases [1].

The term mast cell activation disease represents a stack of disorders described 
by:

1) The pathological mast cell accumulation in conceivably any or all organs and tissues as well as;

2) Atypical release of variable subsets of mast cell mediator [2].

The mast cell activation disease encompasses diseases described by the buildup of genetically modified mast cells and additionally unusual release of these cell mediators, influencing functions in possibly every organ system, regularly without causing variations from the norm in routine laboratory or radiologic testing. In most of the cases associated with mast cell activation disease, the diagnosis is achieved through relatively non-invasive examination. Viable treatment regularly comprises just of antihistamines and mast cell membrane-stabilizing compounds supplemented with medications focused at particular side effects and complications [2].

In most patients, the cause of the disease is from the activating mutation (D816V) in the gene coding for the stem cell factor receptor c-kit, which is present on mast cells. The resulting effect is the auto phosphorylation of the receptor, which is responsible for uncontrolled mast cell proliferation. Mast cell activation disease is currently recognized to likely be significantly pervasive and along these lines ought to be considered routinely in the differential diagnosis of patients with incessant multisystem polymorbidity or patients in whom an absolutely diagnosed major ailment does not well account for the totality of the patient's presentation. This research looks into creative ways of inhibiting the uncontrolled release of bioactive mediators into the body responsible for causing mastocytosis with the polyphenol tetracycline. This method used is creative synthesis and associative thinking. I am taking an out of the box thinking about mast cells and the possibility of using tetracycline for the treatment of mastocytosis.

\subsection{Technical Background}

The process of hematopoiesis has to do with the differentiation of multipotent cells into blood and immune cells. These multipotent hematopoietic stem cells give rise to many different cell types which include the cells of the immune system and that of the red blood cells, as seen in Figure 1 [3] [4].

Mast cells are immune cells of hematopoietic source found in every single human tissue, particularly at the environmental interfaces. They go about as both effector and coordinator cells and assume a focal part in modifying and intrinsic immunity [6] [7]. Their critical part in immunological and also non-immunological procedures is reflected by the extensive number of mediators ( $>200)$ including pre-stored ones, for example, histamine and tryptase and in addition numerous mediators that are resynthesized as a response to the non-immune or allergic triggers, for example, chemokines and cytokines, through which the mast cells may impact other different cells [8]. Their developed multitudes of sensory and response systems induce different chaos when mast cells defect develops. 


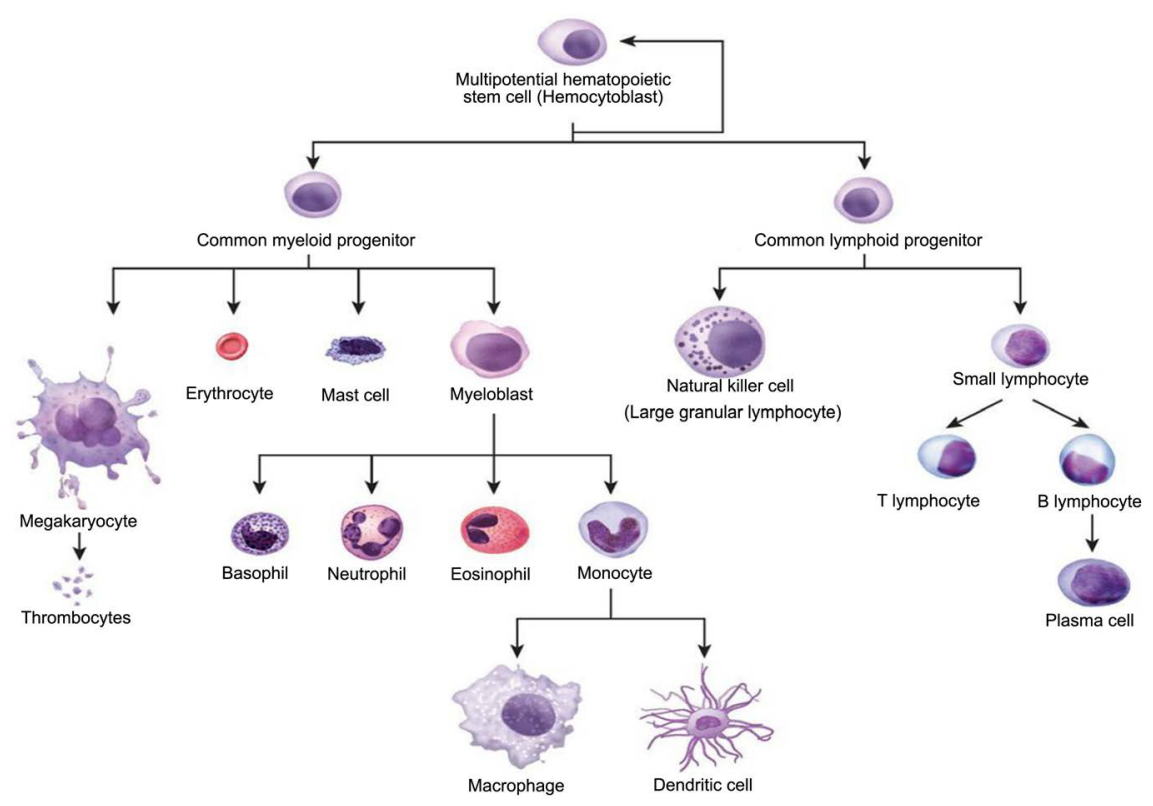

Figure 1. Image of hematopoietic stem cell breakdown [5].

The mast cell is a one of a kind effector part of the immune system described by the existence of metachromatically staining secretory granules, surface expression of the high affinity of $\operatorname{IgE}$ receptor ( $\mathrm{F} c \varepsilon \mathrm{RI}$ ), and localization at tissue sites which are adjacent to the microvasculature and at mucosal and epithelial surfaces [9]. The basophils, eosinophils, neutrophils, platelets, macrophages, and certain subsets of lymphocytes additionally contain secretory granules (Figure 2); yet of these granulated cells just the mast cell and basophil express FceRI. FceRI expression was once thought-out as exclusively for mast cells and basophils, yet two groups have now given solid confirmation that the epidermal langerhans' cell transcribes and expresses the entire tetrameric FceRI molecule on the surface [10]. It has also been discussed that the FceRI presence on mast cells and basophils empowers these two cells to be actuated by the adhering of the IgE to $F c \varepsilon R I$ and resulting cross-linking when a particular antigen is encountered.

The acknowledgment that mast cells discharge an extensive variety of proinflammatory, immunomodulatory, and mitogenic cytokines, mediators that are lipid-derived, and nonpartisan proteases and also the exhibition of functional surface IgG receptors on these cells propose that mast cells most likely assume a more central part in immune and inflammatory processes than those customarily considered. The creation of immunomodulatory cytokines, for example, interleukin-4 (IL-4), by mast cells which can prompt T-helper cell differentiation, is one case of how mast cells may work as regulators and additionally effector components of the immune response as observed in Figure 3.

Figure 4 shows the response mechanism of mast cells. Despite the fact that mast cells differ from the pluripotential hematopoietic immature microorganism, the conferred precursors are not yet distinguishable in the blood. The progenitor forms transverse the vascular space to gain passage to tissue sites where 


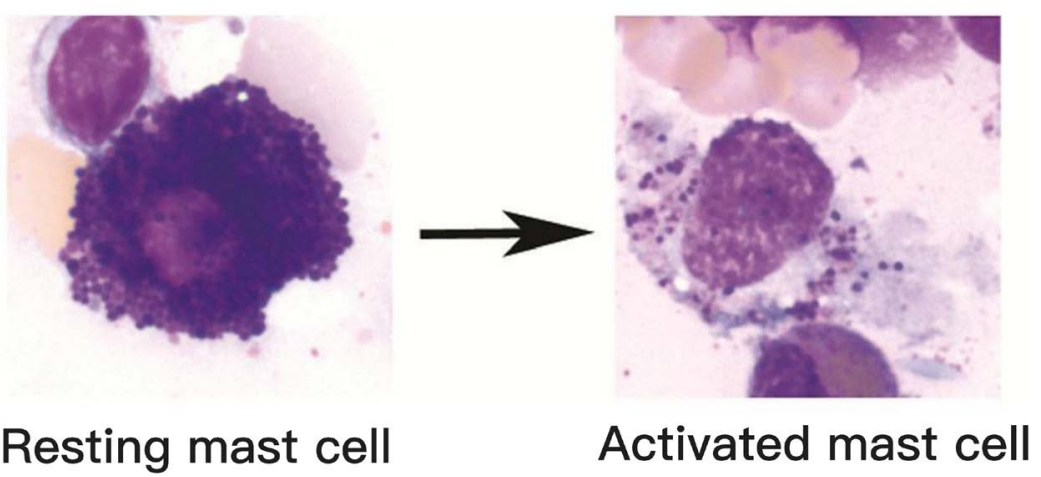

Figure 2. May-Grünwald/Giemsa stain of a resting human mast cell and a mast cell following activation-induced degranulation. Note the loss of granule staining. Mast cells obtained from the human bone marrow, magnification $1000 \times[2]$.

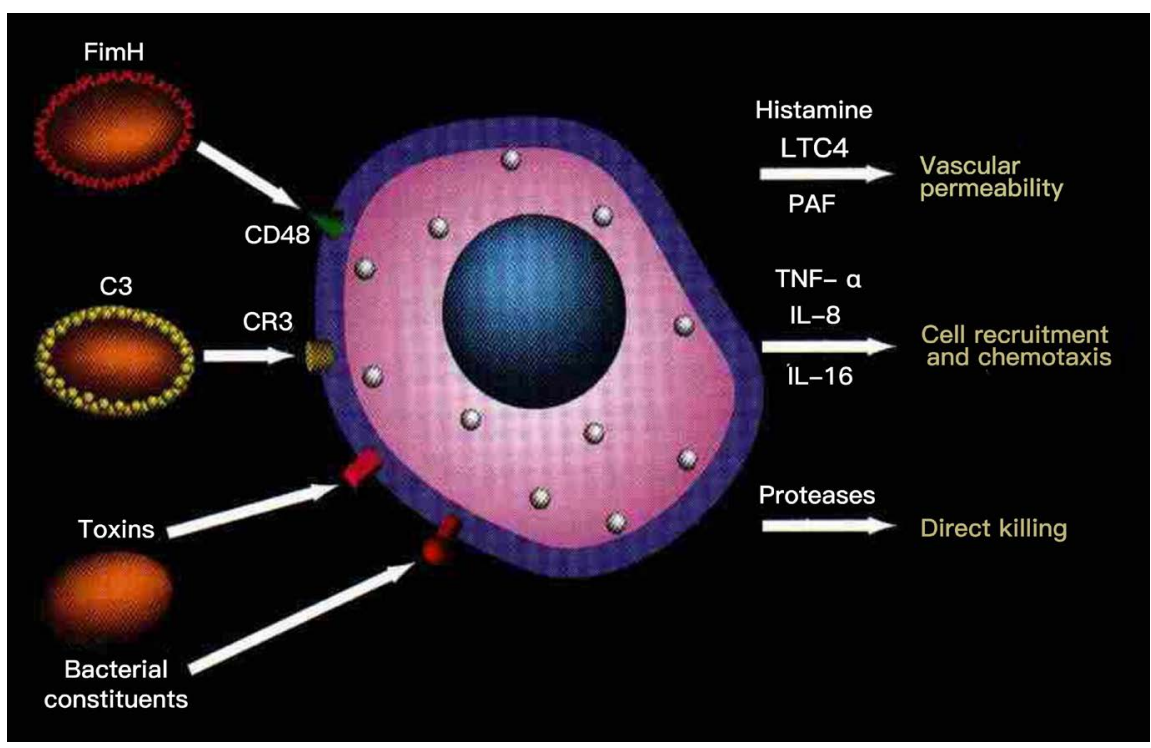

Figure 3. Mast cell-microorganism interactions. Microorganisms such as bacteria or parasites or their products interact with mast cells through specific receptors. This interaction results in mast cell activation and mediator release which elicit an inflammatory response or direct killing leading to bacterial clearance [11].

there will be more proliferation, differentiation, and maturation can happen in light of tissue and organ specific factors [9]. Conversely, basophils develop completely in the bone marrow and are terminally differentiated, the short-lived members from the blood granulocyte compartment where they react to inflammatory mediators by endothelial cell adhesion, extravascular migration, chemotaxis, and activation at the sites of particular inflammation [9].

\subsection{Mast Cell Activation/Secretion Coupling}

At the point when mast cells are exposed to particular multivalent antigen or immune complexes, cross-connecting of FceRI or FcyRIII brings about a unified noncytolytic series of events termed "activation". Activation by Fc\&RI cross linking brings about the cell degranulation or "exocytosis" indicated by a discharge of 


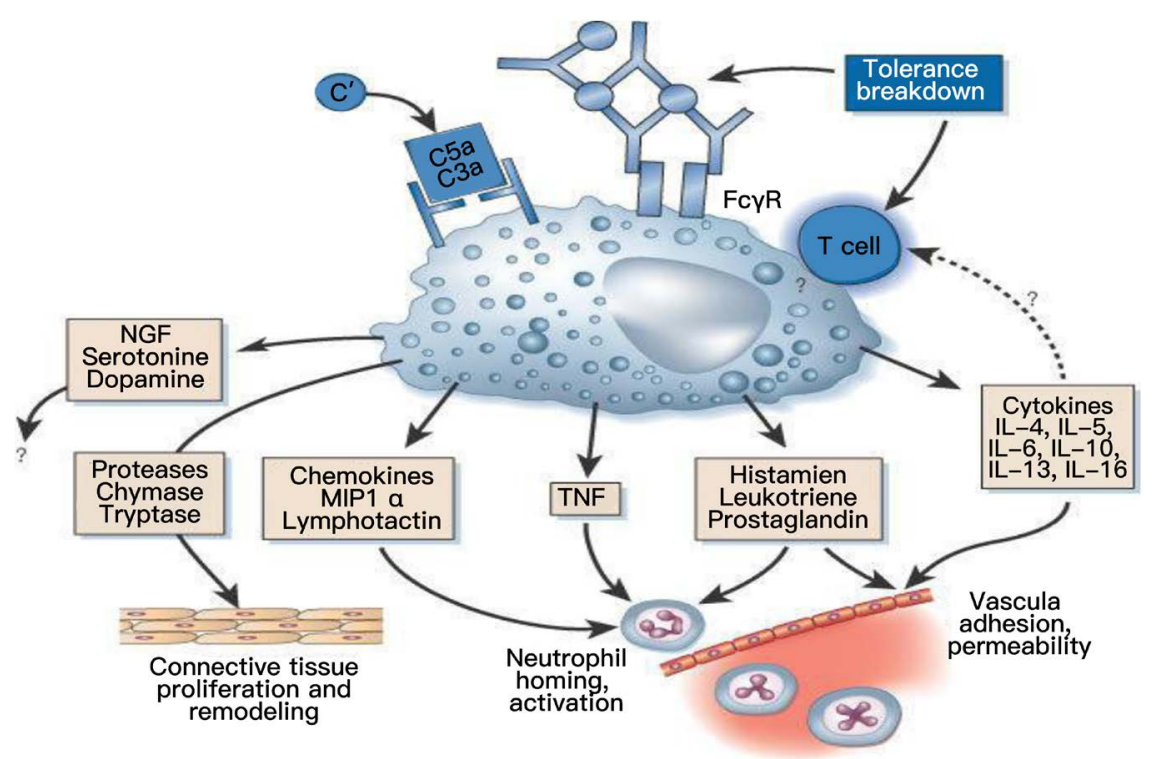

Figure 4. Mast cells are known to be the essential responders in allergic reactions, coordinating responses to small measures of allergens. A lot of recent observations demonstrate that they may likewise have a key part in organizing the early phases of immune system illnesses, especially those including auto-antibodies [12].

bioactive mediators from secretory granules, the biosynthesis and discharge of recently formed mediators gotten from arachidonic acid, and a wide panel of cytokines that are synthesized or secreted, as seen in Figure 5 [9].

The monomeric IgE binding to FcERI as such is thought not to bother the receptor or to bring about cellular events. The gathering of FceRI by resulting binding of multivalent antigen triggers mast cell activation. The earliest perceived event is phosphorylation of particular substrates, including autophophorylation of the $\beta$ and $\gamma$ subunits and phospholipase $\mathrm{C} \gamma$ (PLC $\gamma$ ) [14] [15] by means of tyrosine kinase activity, which copurifies with IgE receptor complexes. Three kinases p56lyn, pp60c-src, and p62c-yes are activated after FceRI is cross-linked [16]. In addition, it appears that in any event some of these tyrosine kinases closely correlate with FceRI and are in charge of the initial phosphorylation of PLC $\gamma 1$, potentially through interaction with a conserved motif in the cytoplasmic part of the FceRI-B and FceRI- $\gamma$ chains [17]. The activation of PLC $\gamma$ l constitutes one early transduction pathway; a second pathway includes tyrosine phosphorylation of a 72-kd substrate known as pp72. The resulting events in the pp72 pathway are obscure [18]. The development in intracellular calcium starts activation of calmodulin-dependent pathways, including the phosphatase calcineurin. Calcineurin possibly controls the activity of various transcription factors that are imperative to cytokine gene expression in T lymphocytes [19] and mast cells [20]. It is possible that additional mechanisms are responsible for altering the quantity of DNA-binding proteins that manage transcription of extra genes including those that encode cytokines. The various bioactive molecules provided by the mast cells are simply considered as results of three compartments: preformed 


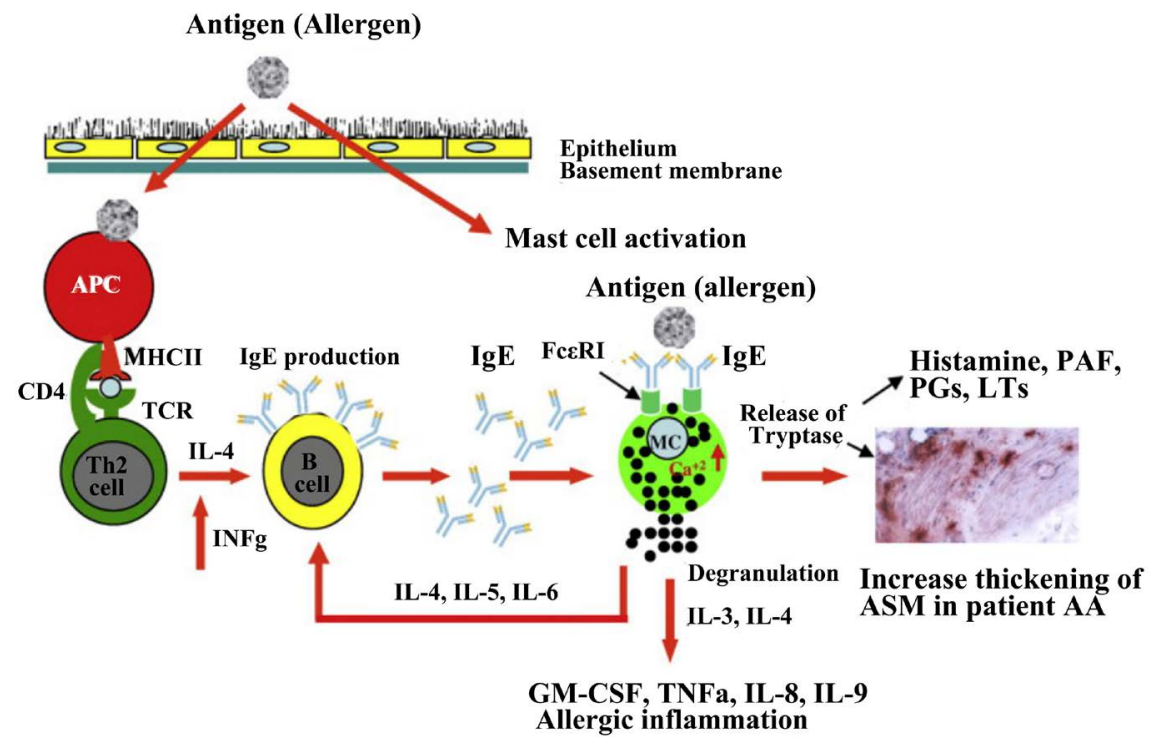

Figure 5. Mast cells in development of allergy [13].

secretory granule middle people and deciphered and deciphered mast cell cytokines. Table 1 shows different mast cell mediators.

\subsection{Roles of Mast Cells in Acute Inflammation}

Various research in mast cell-deficient and reconstituted mice have exhibited that mast cells in particular, though restricted, models of inflammation enhances many characteristics of immunologically non-specific acute inflammatory responses [11]. These reactions are indicated by an influx of leukocytes (mostly neutrophils), edema, and changes in the caliber and permeability of the microvasculature. From experimental procedures, mast cells have appeared to be required for the full expression of the tissue swelling and leukocyte infiltration related with the response to the epicutaneous use of PMA or to the intraperitoneal infusion of thioglycollate [21]. Mast cells have likewise been observed to be essential for the induction of a neutrophil influx in immune complex-mediated reactions. This effect has been ascribed to the capacity of mast cells to make and secrete TNF- $\alpha$, as TNF- $\alpha$ levels were essentially diminished in the mast cell-lacking $\mathrm{W} / \mathrm{Wv}$ mice in addition to the reduction in local neutrophil accumulation. Mast cell reconstitution adjusts TNF-a levels and neutrophil activation [22]. This induction of immune complex-mediated mast cell-dependent inflammation appeared to include IgG Fc receptors. This proposes that mast cells may add to as well as start these responses, as mouse mast cells express $\mathrm{Fc} \gamma \mathrm{RII}$ and $\mathrm{Fc} \gamma \mathrm{RIII}$ [23].

\subsection{Mastocytosis}

Mastocytosis is a moderately uncommon disease portrayed pathologically by mast cell hyperplasia in the skin and other organ, for example, the gastrointestinal tract, bone marrow, lymph nodes, liver, and spleen. Some of the medical 
Table 1. Mast cell mediators [9].

Preformed secretory granule mediators

- Histamine

- Proteoglycans

- Serine proteases

- Chymases

- Tryptases

- Carboxypeptidase A

Lipid-derived mediators (newly formed)

- Leukotriene

- Leukotriene C4, D4, and E4 (SRS-A)

- Prostaglandin D2

- Platelet-activating factor (PAF)

Mast cell-derived cytokines

Proinflammatory Cytokines

- TNF-a

- IL-1a

- IL-1b

- IL-6

- MIP family

Mitogenic cytokines and/or growth factors

- IL-3

- IL-4

- IL-5

- IL-10

- GM-CSF

Immunodulatory cytokines

- IL-1a and IL-1b

- IL-4

- IL-10

- IFN-y

symptoms observed with this condition includes, but not limited to, urtication, abdominal pain, pruritus, nausea, vomiting, headache, flushing, diarrhea, and vascular instability. Urticaria pigmentosa, the most well-known skin sign of mastocytosis (shown in Figure 6), was depicted by Nettle-transport in 1869 [24]. Over the top quantities of mast cells were identified in the lesions of urticaria pigmentosa by Unna in 1887 (Unna, 1983). In 1949, Ellis [25] detailed the instance of a child with urticaria pigmentosa with the first posthumous evidence implying that mast cell hyperplasia in skin could be related to systemic disease. From that point forward, there has been an increase in acknowledgment of the clinicopathologic diversity of mastocytosis [26]. These improvements have been accompanied by a quick expansion in learning of the development, differentiation, and biologic expression of mast cells, including the recognition of the inception of mast cells from CD34+ human pluripotent cells [26], the description of the growth factor of mast cell which includes interleukin (IL)-3 [27] as well as the c-kit ligand or stem cell factor (SCF) [28], and the depiction of various pleomorphic and redundant mast cell-derived mediators as shown in Figure 7 [11]. 


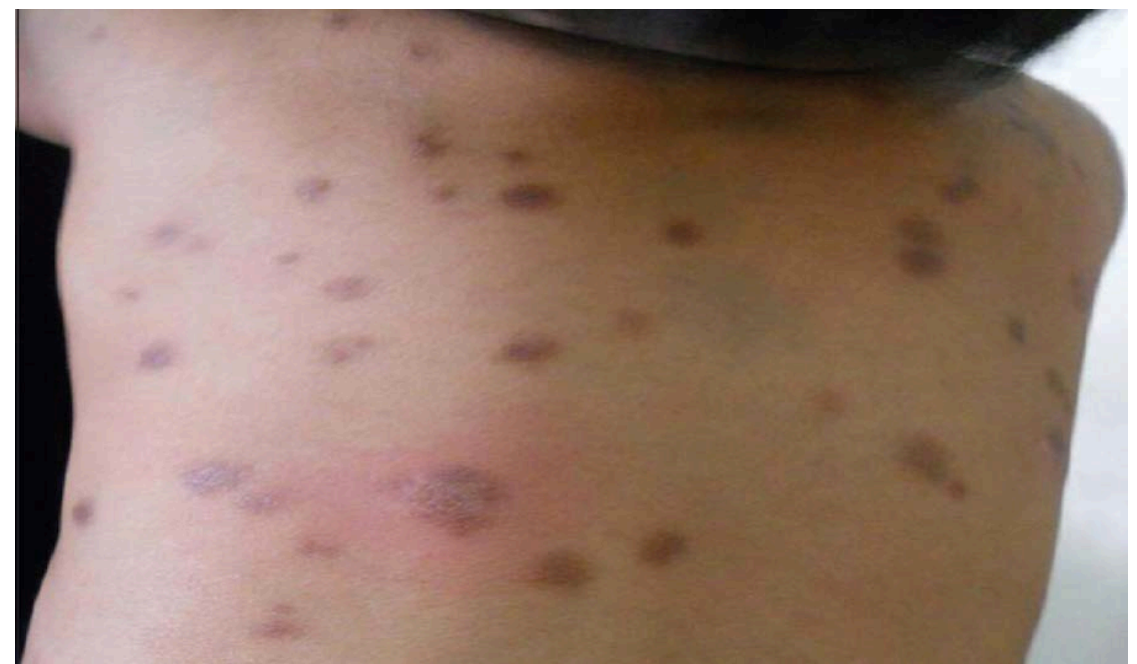

Figure 6. Urticaria pigmentosa lesions on a child [29].

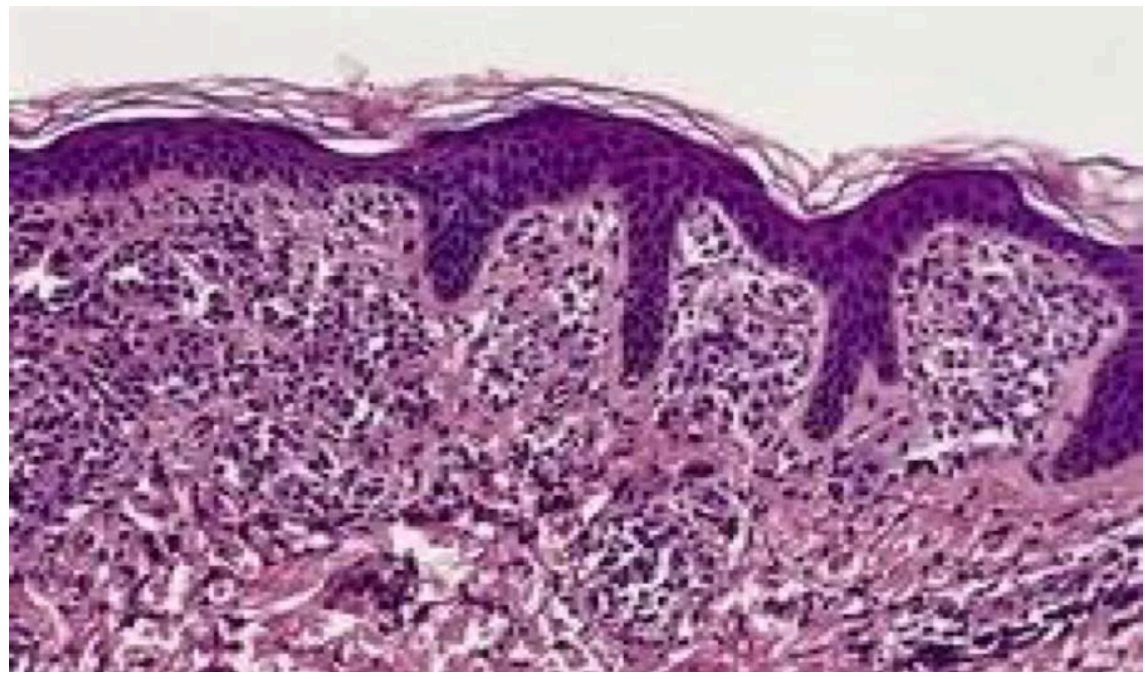

Figure 7. admixture of perivenular lymphocytes and scattered eosinophils [30].

It is unknown the extent to how prevalent mastocytosis currently is, it has been accounted for to be the diagnosed in 1 patient for each 1000 to 2500 new cases found in a dermatology practice or dermatology clinic [31] Mastocytosis can happen at any age and exhibits a slight male-to female predominance. Rare instances of familial mastocytosis have also been reported [32].

Classification

The characterization has been refined by the National Institute of Health by including a group of patients who were named as having lymphadenopathy mastocytosis with eosinophilia [33]. Such patients show, as the term implies, conspicuous rapid advancement of lymphadenopathy, documented mastocytosis, and eosinophilia. Plainly, the mast cell disorders in category II through IV have a more rapid course than the disease as depicted in category I. In classification II the associated hematologic disorder to a great extent decides the course of the disease. Patients with mast cell leukemia have lesser chances of survival in 
spite of treatment. Patients with mastocytosis in category IV for the most part live just 2 - 4 years after diagnosis, without chemotherapy.

Other characteristics of mastocytosis are useful in characterizing the categories of patients. For instance, most patients with the indolent variety of the disease have urticaria pigmentosa or diffuse cutaneous mastocytosis sooner or later. However, in categories II through IV, urticaria pigmentosa or diffuse cutaneous mastocytosis is a variable finding. It was additionally seen that patients with mastocytosis that is developing into a leukemic procedure may encounter lost urticaria pigmentosa, should it be present [26]. Figure 8 shows a concept map of the classification of mastocytosis.

\subsection{Tetracycline}

In addition to the antibiotic properties of tetracycline, they have also been discovered to exert a number of pleiotropic anti-inflammatory and immunomodulatory activities These include the capacity to inhibit metalloproteinases (MP), which are an enzyme class involved in important cell functions, for example, the shedding of dissolvable mediators and their receptors from the cell surface, and connection with, the remodeling of the extracellular matrix. It was additionally detailed that doxycycline (DOXY) at therapeutic concentrations $(1-5 \mathrm{ug} / \mathrm{ml})$ suppresses Ig secretion to a significant extent and class switching by in vitro activated murine B cells [35].

Although the complex chemistry of the tetracyclines is beyond the scope of this thesis, in order to appreciate their ability to interact with a wide variety of biomolecules, a simple knowledge of the main features of these compounds is important to. Tetracyclines, such as DOX, and minocycline (MIN), all possess a four-ring core that is attachedat various side groups (Figure 9). The dimethylamino group, which is located at the $\mathrm{C}_{4}$ carbon on the upper half of the molecule,

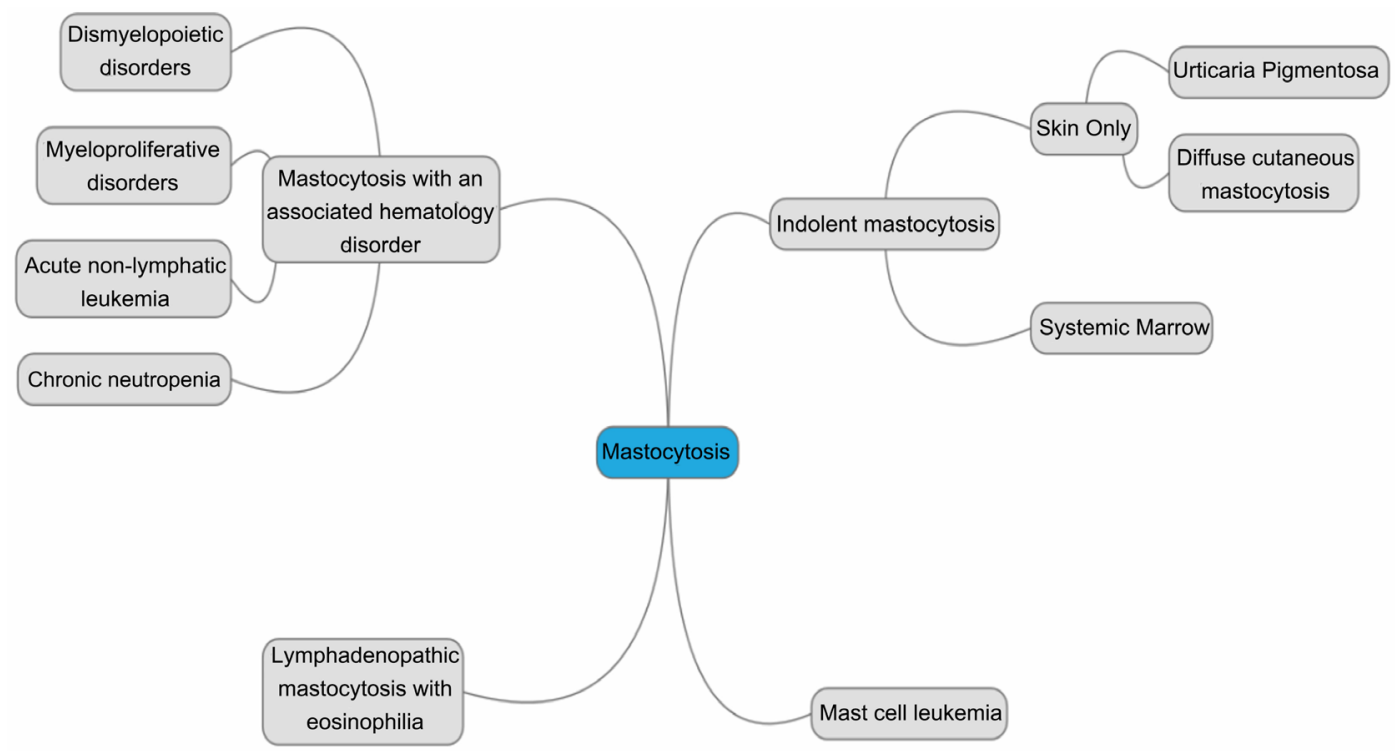

Figure 8. Concept map of Mastocytosis classification [34]. 
Doxycycline

Minocycline

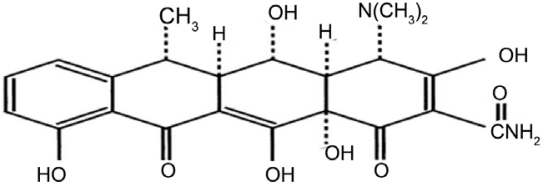<smiles>C[C@H]1C(O)=C(C(N)=O)C(=O)[C@]2(O)C(O)=C3C(=O)c4c(O)ccc(O)c4C[C@H]3C[C@H]12</smiles><smiles>NC(=O)C1=C(O)CC2CC3Cc4cccc(O)c4C(=O)C3=C(O)C2(O)C1=O</smiles>

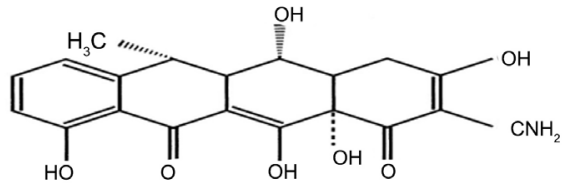

Figure 9. Chemical structure of tetracyclines [36].

has shown to be of major importance to their characteristic antimicrobial activity.

Chemically modified tetracyclines (CMTs) also known as 4-De-dimethylamino tetracyclines lack antimicrobial activities in vivo and this may be due to the inability of the molecule to adapt the zwitterionic form that will be necessary for activity [37]. In any case, CMTs do hold the capacity to bind other non-microbial targets, for example, matrix metalloproteinases (MMPs), encouraging their utilization in the treatment of other disease processes [37]. The oxygen-rich lower half of the molecule is very important for binding to both prokaryotic and eukaryotic targets, and obstruction with this area decreases or disposes of the potency of the drug [38]. This region is applicable as a site for the metal ion chelation. The binding of tetracycline to proteins, including the Tet Repressor protein (TetR), might be enormously improved when the tetracycline is complexed with divalent metal ions, for example, $\mathrm{Ca}^{2+}$ or $\mathrm{Mg}^{2+}$ [39]. The binding of tetracycline to MMPs is believed to be intervened by the chelation of structural and catalytic $\mathrm{Zn}^{2+}$ ions inside the enzyme (Figure 10) [38] [40].

Figure 11 above shows the dynamic nature of the tetracycline. The molecule has a modifiable upper region to improve the efficiency of its interaction and a lower non modifiable region. Figure 11 demonstrates the tetracycline's solid skeleton with the possession of the four rings, groups and the upper and lower sides of the molecule in the manner they are usually called. A number of the chemical alterations of both the first and second generation tetracyclines created fluidly active or inactive compounds. A tetracycline which is active (antibacterial activity) must have a linearly arranged DCBA naphthacene ring system with an A-ring C1-C3 di-keto substructure and an exocyclic C2 carbonyl or 


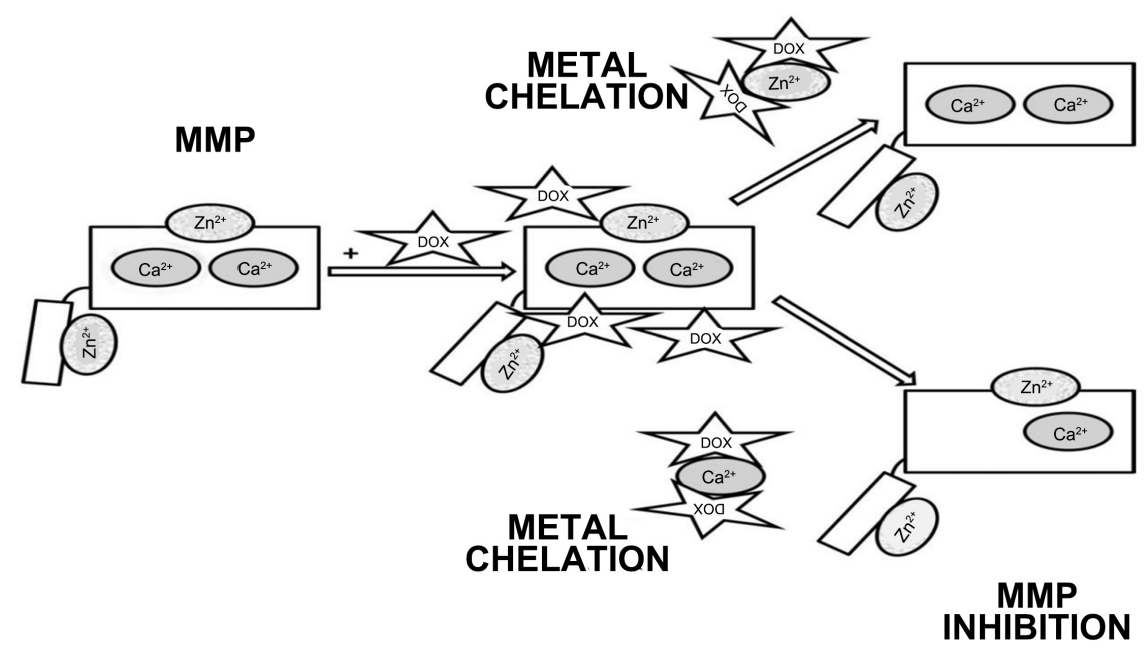

Figure 10. Illustration of means by which doxycycline through zinc and calcium chelation may inhibit matrix metalloproteinases (MMPs) [41].

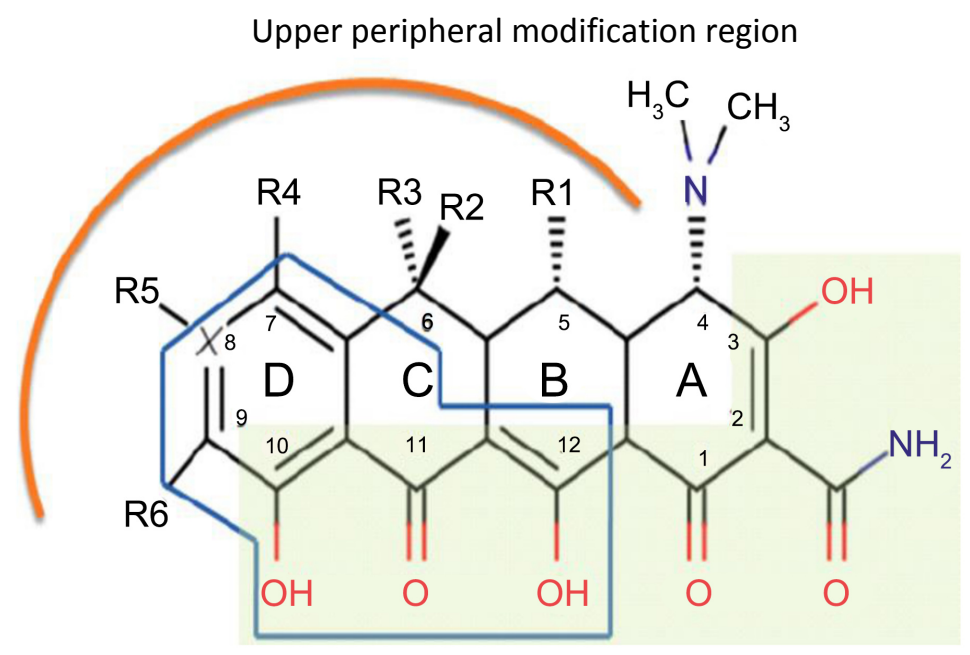

lower peripheral non modifiable region

Figure 11. Structure-Activity-Relationship (SAR) of Tetracyclines (TCs). Shaded: Contact region with 30S rRNA. In blue polygonal: same anthracycline region [42].

amide group. All Tetracycline that perform as an inhibitor of protein. Synthesis in bacteria require the amino group in position $\mathrm{C} 4$ and keto-enolic tautomers in position $\mathrm{C} 1$ and $\mathrm{C} 3$ of the $\mathrm{A}$ ring [42].

\subsection{Matrix Metalloproteinase Inhibition by Tetracyclines}

One of the best characterized non-antimicrobial characteristics of the tetracyclines is their ability to inhibit Matrix Metalloproteinase (MMP) family members of endopeptidases. The MMPs are a group of zinc-dependent proteases that are associated with numerous physiological and pathophysiological processes including embryogenesis, tissue remodeling, inflammation, and tumor invasion [43]. MMPs can be subdivided in light of crude substrate specificities into the collagenases, gelatinases, stromelysins, and membrane-type MMPs (MT-MMPs) 
[44]. The collagenase groups consist of MMP-1, MMP-8, and MMP-13, and all cleave fibrillar collagens (type I and type III). Collagen parts subsequently denature into gelatins.

The gelatinases incorporate MMP-2 and MMP-9, proteolyze the gelatins. The gelatinases likewise degrade basement collagen (type IV). The stromelysins consists of MMP-3, MMP-7, MMP-10, and MMP-11, and they are fit for debasing proteoglycans, laminin, fibronectin, collagen IV, and others. The cell membrane-anchored MT-MMP consists of six distinctive MMP, of which MT1MMP is the best described [45]. The suppression of MMPs is gainful in numerous pathological conditions in which MMP-mediated proteolysis of the extracellular matrix (ECM) adds to the pathogenesis, for example, heart remodeling, tumor invasion, and inflammation [43] [46].

\subsection{Reactive Oxygen Species}

There is an excess production of reactive oxygen species under many pathological conditions, for example, myocardial I-R injury and inflammatory processes which can further lead to the oxidative destruction or the dysfunction of many cellular parts. Reactive oxygen species (ROS) have been said to be highly reactive and consist of free radicals superoxide $\left(\mathrm{O}_{2}\right)$ and hydroxyl radical $(\mathrm{OH})$, the non-free radicals hydrogen perioxide $\left(\mathrm{H}_{2} \mathrm{O}_{2}\right)$, hypochloride $(\mathrm{HOCl})$, and peroxynitrate $\left(\mathrm{ONOO}^{-}\right)$[47]. Both DOX and MIN have a multiple-substituted phenol ring similar to vitamin $\mathrm{E}$ which is the major key to the ROS-scavenging ability of these compounds. The phenol ring reacts with a free radical to create a more stable and unreactive phenolic radical. It is said that MIN has a more superior scavenging ability and this can be due to the presence of diethyamino group on the phenolic carbon which is exclusive to MIN and it provides the improved steric hindrance [48].

\subsection{Proapoptotic Properties of Tetracyclines}

In a study completed to observe the cytotoxic impact of Tetracycline Analogs (TCNAs) (Doxycycline, Minocycline and COL-3) in Acute Myeloid Leukemia HL-60 Cells, TCNAs was able to induce a cytotoxic effect in the human leukemia-60 (HL-60) cells in a concentration and time-dependent way. The half maximal inhibitory concentration (IC50) was evaluated after $24 \mathrm{~h}$ of incubation with the TCNAs. An IC50 of $1.3 \mu \mathrm{g} / \mathrm{ml}$ was reported, which shows higher sensitivity of the cells to the tetracycline derivative COL-3 than to DOXY and MINO, which was reported to have an IC50 of 9.2 and $9.9 \mu \mathrm{g} / \mathrm{ml}$, respectively These IC50s are in the low scope of sensitivities detailed in cancer cell lines. IC50 in the range of $3-10 \mu \mathrm{g} / \mathrm{ml}$ was reported for COL-3, and $10-20 \mu \mathrm{g} / \mathrm{ml}$ for DOXY [49] [50]. MINO has been reported to repress proliferation of epithelial cancer cell lines with IC50 levels of around $60 \mu \mathrm{mol} / \mathrm{L}$ that compare to $27 \mu \mathrm{g} / \mathrm{ml}$ [51].

The inhibitory impact of DOXY and COL- 3 in HL- 60 cells was reported by Tolemeo et al. [52]. They reported the IC50s for DOXY and COL-3 to be 8 
$\mu \mathrm{g} / \mathrm{ml}$ and $7 \mu \mathrm{g} / \mathrm{ml}$, respectively. The results for DOXY were found to be in concurrence with the study, however the IC50 for COL-3 was lower in the study. This distinction in IC50 can be clarified by various tests and incubation time utilized in the study. The feasibility with resazurin tests was examined, and along these lines analyzed the effects of TCNAs on the metabolic activity of cell mass, while Tolemeo et al. assessed the individual cell viability utilizing trypan blue exclusion assay. They likewise reported AC50 (condition that is able to induce 50\% apoptosis) for DOXY and COL-3 to be 15 and $16 \mu \mathrm{g} / \mathrm{ml}$, respectively, although they didn't examine the underlying apoptotic mechanisms. In the study carried out, COL-3 in a concentration of $5 \mu \mathrm{g} / \mathrm{ml}$ prompted cell death in HL-60 cells. Other studies that have been published have indicated significant apoptotic and growth inhibitory effects of COL-3 out of a grouping of $10 \mu \mathrm{g} / \mathrm{ml}$ in a wide scope of human tumor cell lines and xenografts [53] [54] [55]. TCNAs have been reported to induce apoptosis in different disease cells; be that as it may, the reported biochemical events that underlies the TCNAs-induced cell death differs [56] [57]. The mitochondrion produces energy for a cell and furthermore controls cell death by releasing factors that promote cell death into the cytosol.

\subsection{Polyphenols}

Polyphenols are an anatomical class of mostly natural (Figure 12), yet synthetic or semisynthetic, natural chemicals portrayed by the evidence of huge amounts of phenol structures. The number and attributes of these phenol structures underlie the one of a kind physical, chemical, and biological properties of specific members of the class. Some examples of this include tannic acid and ellagitannin. The historically essential chemical class of tannins is a subset of the polyphenols [58] [59].

Magnolol and honokiol are phenolic structural isomers that are separated from the bark of Magnolia 15ontelu that have appeared to strongly hinder the degranulation of RBL-2H3 cells actuated by IgE- antigen complex and additionally the creation of cytokines; IL- 4 and TNF- $\alpha$. In addition, the two compounds

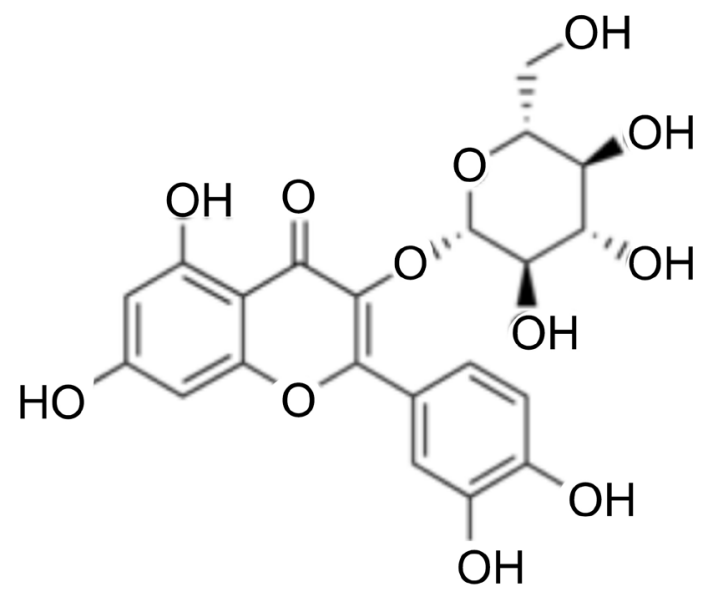

Figure 12. Structure of a plant-derived polyphenol, quercetin-3- $O$-glucoside [60]. 
powerfully repressed PCA reactions in mice prompted by IgE-antigen complex dose dependently at dosages of 10 and $50 \mathrm{mg} \cdot \mathrm{kg}^{-1}$ [62].

Table 2 shows some of the naturally occurring mast cell stabilizers. Resveratrol, is a phytoalexin, stilbene polyphenolic compound found in grapes, berries and peanuts. It suppresses the presence of inflammatory cytokines, for example, TNF- $\alpha$, IL-6 and IL-8 in PMACI-induced-HMC- 1 cells and diminished the levels of intracellular $\mathrm{Ca}^{2+}$ [63]. Similarly, the anti-allergy activity of polydatin, a resveratrol glucoside, fundamentally diminished FceRI-mediated degranulation in IgE-sharpened RBL-2H3 cells in a dose dependent way $(1-100 \mu \mathrm{M})$ and repressed the IgE-dependent PCA response in mice $\left(300 \mathrm{mg} \cdot \mathrm{kg}^{-1}\right.$ [64]. Curcumin

Table 2. Naturally occurring mast cell stabilizers [61].

\begin{tabular}{|c|c|c|c|c|}
\hline $\begin{array}{c}\text { Source of } M C \\
\text { Stabilizers }\end{array}$ & Compound Name & Mast cell population & Elicitor & In vivo evaluation \\
\hline \multirow[t]{13}{*}{ Flavonoids } & Luteolin & HCMCs & anti-IgE & Unspecified \\
\hline & & BMMCs & Anti-IgE and IL-3 & \\
\hline & & Basophils & Antigen & \\
\hline & & RBL-2H3 & & \\
\hline & Diosmetin & RBL-2H3 & Antigen & Unspecified \\
\hline & Apigenin & Basophils & Anti-IgE and IL-3 & Unspecified \\
\hline & Quercetin & RBL-2H3 cells & $\begin{array}{l}\text { Anti-IgE, Phorbal-12-myristate-13-acetate, } \\
\text { calcium ionosphore A23187 and PMACl }\end{array}$ & Unspecified \\
\hline & Fisetin & RBL-2H3 & Anti-IgE, PMACl & Unspecified \\
\hline & & HMC-1 & PMACl & \\
\hline & Kaempferol & RBL-2H3 cells & $\begin{array}{l}\text { anti-IgE, phorbal-12-myristate-13-acetate, } \\
\text { calcium ionophore A23187 and PMACl }\end{array}$ & Unspecified \\
\hline & Ginkgetin & BMMCs & $\mathrm{KL}$ & Unspecified \\
\hline & EGCG & $\begin{array}{c}\text { RPMCs } \\
\text { RBL-2H3 cells }\end{array}$ & Compound $48 / 80$ & PCA reaction in rats \\
\hline & Silymarin & & Compound $48 / 80$ & PCA reaction in rats \\
\hline \multirow[t]{7}{*}{ Coumarins } & Scopietin & RPMC & PMACl & \\
\hline & Scaporone & & Anti-DNP IgE & PCA reaction in rats \\
\hline & Artekeiskeanol A & RBL-2H3 cells & Calcium ionophore A23187 & Unspecified \\
\hline & Selinidin & & Antigen & Unspecified \\
\hline & $\begin{array}{l}\text { 5-Methoxy-8-(2-hydroxy-3-butoxy- } \\
\text { 3-methylbutyloxy)-psoralen }\end{array}$ & & $\mathrm{KL}$ & Unspecified \\
\hline & Cinnamic acid & RBL-2H3 cells & Antigen & Unspecified \\
\hline & Ellagic acid & & Anti-DNP IgE & PCA reaction in rats \\
\hline \multirow[t]{4}{*}{ Phenols } & Magnolol and honokiol & RBL-2H3 cells & IgE-antigen & PCA reaction in rats \\
\hline & Resveratol & & PMACl & PCA reaction in rats \\
\hline & polydatin & RBL-2H3 cells & Anti-IgE & PCA reaction in rats \\
\hline & Curcumin & RBL-2H3 cells & Antigen & PCA reaction in rats \\
\hline
\end{tabular}


is a polyphenolic compound found in Curcuma longa and related species. Curcumin has exhibited anti-allergic activity in both in vitro and in vivo models. It fundamentally constrains antigen-induced degranulation in a dosage dependent way $(1-10 \mu \mathrm{M})$ in both RBL-2H3 cells and BMMCs and in addition restrains PCA reactions in mice at $0.5-50 \mathrm{mg} \cdot \mathrm{kg}^{-1}$ dosages. Curcumin fundamentally repressed the expression of mRNA for cytokines; IL-4 and TNF- $\alpha$ in a dose dependent way and additionally their secretion in antigen-stimulated RBL-2H3 cells [63] [65]. The xanthones; mangostin- $\alpha,-\beta$ and $-\gamma$ that are isolated in a sense from the 15onteluk of Garcinia mangostana L. inhibited the histamine release from IgE-sensitized RBL-2H3 cells as a response to the antigen through the repression of the signaling transduction pathway including Syk and PLC $\gamma$ [66].

\section{Methodology}

The method used to obtain results for this thesis is the utilization of associative thinking and creative synthesis from available literature that seem unconnected to develop a new solution for the treatment of mastocytosis.

\subsection{Creative Synthesis}

Creative synthesis is a modern solution for solving existing problems and expanding knowledge. The process of creative synthesis is driven by an innovative drive to solve complex problems in fundamental science and engineering for the purpose or getting novel solutions.

Creative synthesis acts like a guide that prompts advancement of thoughts that are results of the synthesis and can be linked with meta-analysis which is essentially consolidating data from various resources and relating the varied factor. In this instance, tetracycline and tetracycline derived compounds is observed for its inhibitory effect on the production of cytokines such as TNA-a which causes inflammation in mastocytosis.

Creative synthesis recognizes and establishes a complex link between previously unrelated concepts. It is not a particular idea; it is more of a new way to understand what an idea is. Synthesis can be characterized as creative because the new pattern involved in it is a novel construction which is distinct from both the dominant understanding (i.e. thesis) and alternative perspective (i.e. antithesis) [67].

\subsection{Process of Ideation from Innovation DNA}

The process of creating commercially viable ideas is achieved by making use of certain skills identified in the innovator's DNA, these skills are as follows:

- Observation;

- Questioning;

- Networking;

- Experimenting;

- Associative thinking. 
The combination these skills bring about an innovative idea (Figure 13) by making use of the creative skill of an innovator (Figure 14).

The compelling need of this thesis is to find if tetracycline can be used to treat mastocytosis. The questions that are asked as follows:

- What is the cause of mastocytosis?

- How can it be treated?

- How can tetracycline help in mastocytosis treatment?

- Is there a possible combination of tetracycline with other compounds to help improve the treatment?

The data used in this research was obtained from various scientifically published materials such as;

- Scientific publications;

- Text books;

\section{Creative Synthesis}

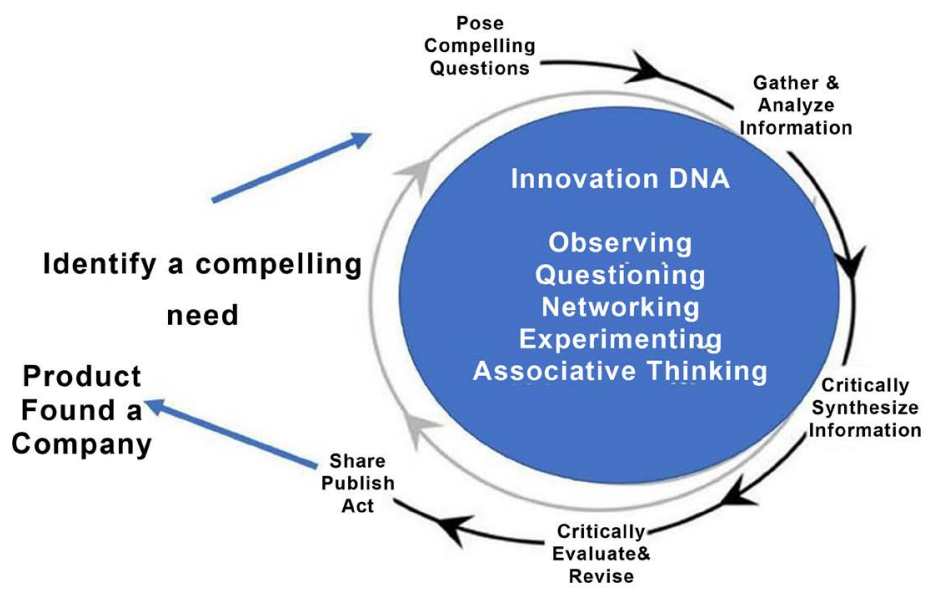

Figure 13. Creative synthesis.

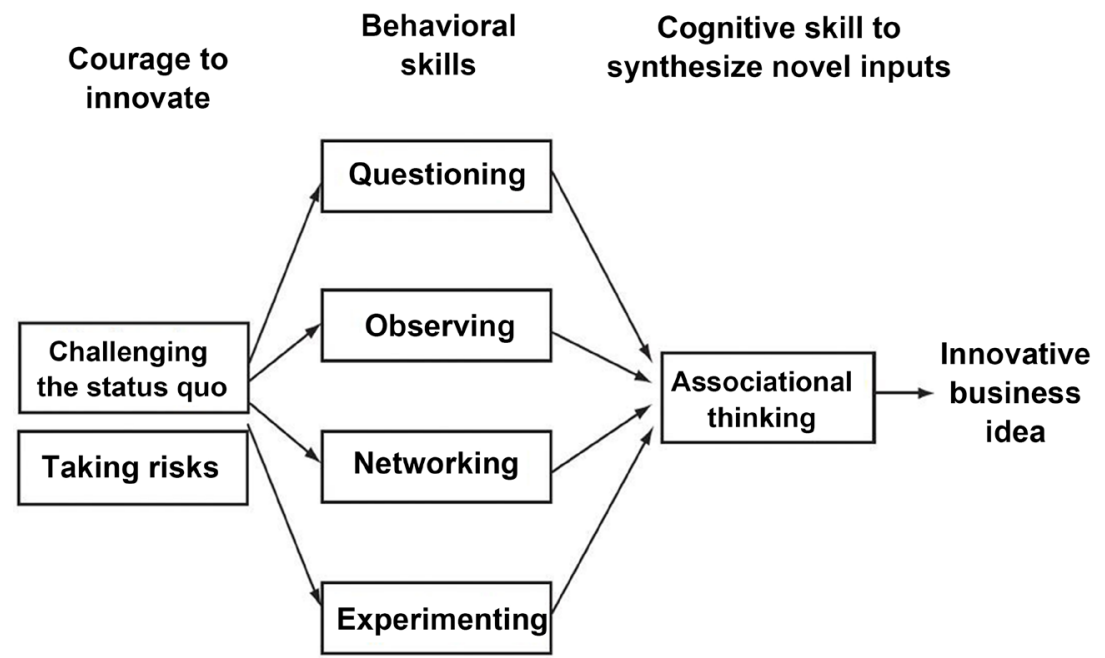

Figure 14. Model shows the creative synthesis skill of an innovator [68]. 
- Library catalogue;

- Online articles.

The data was selected based on the relevance of the methods that are currently used for the treatment of mast cell diseases and inflammatory related diseases.

\section{Results and Discussion}

\subsection{Chemically Modified Tetracycline}

Chemically modified tetracyclines (CMTs) are recently synthesized tetracycline analogues which are without anti-microbial properties and exert a strong anti-collagenase activity. The ability to inhibit the synthesis of nitric oxide (NO), and the expression of NO synthase (iNOS) in j774 cell macrophage is a characteristic that has been shown by most CMTs, which is similar to what is achieved bybroad-spectrum antibiotics, doxycycline and minocycline. NO is a short-lived messenger molecule that performs many functions. In contrast, NOacts a dual role of being a physiological intercellular messenger and secondly, can cause cytotoxic activity. It has been demonstrated that NO can induce apoptotic as well as necrotic cell death, depending on the cell type and on its activation status. In programmed cell death (PCD), or apoptosis, one of the earliest and most consistently observed features, is the induction of a series of cytosolic cysteine proteases, known as caspases. A hierarchic model was proposed by D'agostino et al. where pro-caspase- 8 was activated by an apoptotic stimulus with the liberation of active caspase- 8 into the cytosol and, subsequently, the activation of successive effector caspases such as caspase-2, -3, -6 and -7 acting as a proteolytic cascade [69]. Recent evidence suggests that c-myc, in addition to controlling cell proliferation, can also induce apoptosis during the induction of PCD by Fas or in the presence of cytostatic drugs. CMTs have been shown to possess cytotoxic activities against different cell lines, with some that have the ability to cause PCD in targeted cells [69], although the mechanism as to how they act as apoptotic agents is still not clear.

\subsection{Mast Cell Stabilizers}

Neither ketotifen nor cromolyn are genuine mast cell stabilizers as they don't block inflammatory cytokine discharge. Ketotifen is a histamine-1 receptor enemy that is likewise a weak inhibitor of histamine and prostaglandin discharge through an unknown mechanism. The extra advantage of ketotifen over different antihistamines is that it obstructs the activities of eosinophils generally involved with allergies especially in eosinophilic esophagitis/gastroenteritis. Disodium18 ontelukast18 (cromolyn) was believed to be a "mast cell stabilizer" since it blocked rat mast cells, however is an extremely weak inhibitor of human mast cells, and like ketotifen, it hinders histamine and prostaglandin discharge to some degree, but not inflammatory cytokine discharge, again through an unknown mechanism.

NeuroProtek contains luteolin and quercetin, both of which have been ap- 
peared to prevent the release of each mediator that have been studied from mast cells. The issue is to get enough of these to be consumed orally. In any case, NP can be given together with either ketotifen and additionally cromolyn to the degree that the latter are useful in a few patients [70].

\subsection{Drugs That Interfere with Mast-Cell Symptoms}

There is no treatment that brings about in lasting resolution of the skin sores related with cutaneous or systemic mastocytosis. Normal symptoms of cutaneous or systemic mastocytosis are typically tended to through the administration of non-sedating and longer-acting histamine (H1)-receptor antagonist, for example, loratadine (the starting dosage in adults, $10 \mathrm{mg}$ orally day by day; $5 \mathrm{mg}$ orally every day in kids younger than 6 years old; $10 \mathrm{mg}$ orally daily in children that are 6 years old or older), and cetirizine (starting dosage in adults, 5 to $10 \mathrm{mg}$ orally daily; $2.5 \mathrm{mg}$ orally daily in kids younger than 6 years old; 5 to $10 \mathrm{mg}$ orally daily in kids 6 years old or more). Cysteine-leukotriene-receptor antagonists, for example, Montelukast (10 mg orally daily in adults; $4 \mathrm{mg}$ orally once daily in children younger than 6 years old; $5 \mathrm{mg}$ orally daily in kids within the age of 6 and 14 years old) or the 5-lipoxygenase inhibitor zileuton might be helpful when utilized as a part of conjunction with $\mathrm{H} 1$-and $\mathrm{H} 2$-receptor antagonists [71].

Acetylsalicylic acid (81 to $325 \mathrm{mg}$ orally on once or twice every day in adults) might be gainful in a few patients who have flushing and angioedema (with elevatedamounts of urinary prostaglandin D2 or $11 \beta$-PGF2 $\alpha$ ) if the patient's capacity to get nonsteroidal anti-inflammatory drugs without adverse effects is known. Tricyclic antidepressants (e.g., amitriptyline or doxepine) (25 to $100 \mathrm{mg}$ orally every day depending on the side effect profile in adults) and prochlorperazine (5 to $10 \mathrm{mg}$ orally three or four times daily in adults) might be helpful in light of the fact that they have both histamine H1-receptor antagonism and mast-cell inhibitory properties [72], yet sedation and weight gain diminish the patient's adherence.

Psoralen and ultraviolet A or narrow-band ultraviolet B treatment may reduce the itching and help fade the lesions temporarily [73]. Topical glucocorticoids are for the most part not prescribed, since the lesions typically include substantial body-surface areas.

\section{Conclusions}

When dealing with mastocytosis, there are 4 major problems to put into consideration and should be analyzed, as seen in Figure 15.

With the use of creative synthesis, an innovative solution has to be created which will have to accomplish a couple of things effectively in order to treat mastocytosis completely and they are as follows in Figure 16.

The solution will have to be a product that can attack all four of those issues. The addition of CMT will cause apoptosis of the affected cells, then the addition of 


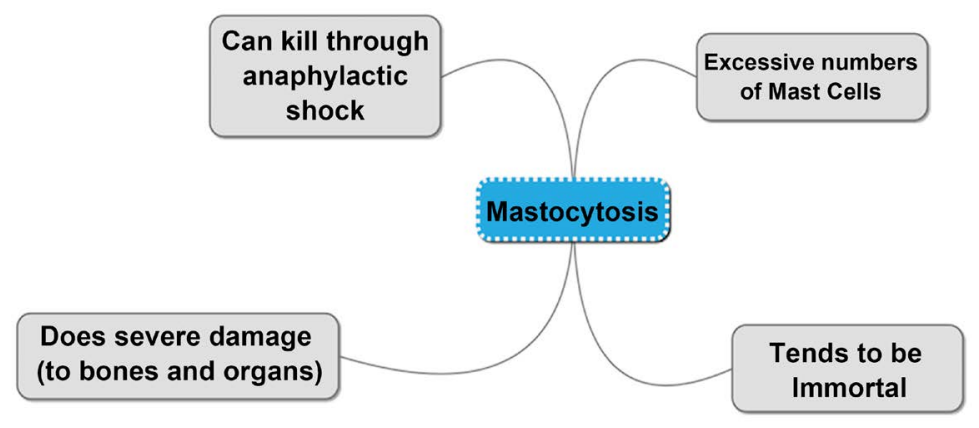

Figure 15. Major problems of Mastocytosis.

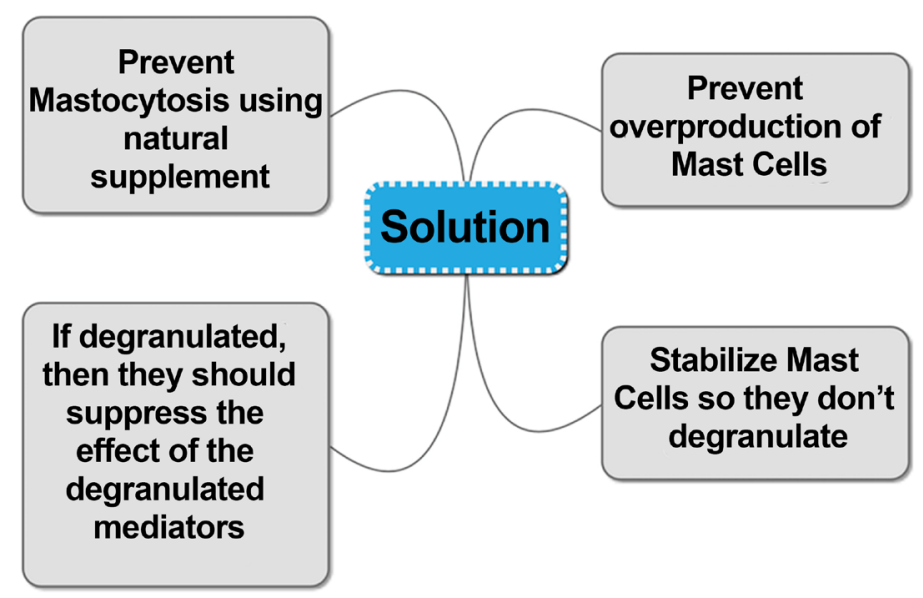

Figure 16. The needs to be met by solution.

other supplements, and compounds that can block the effects of degranulation, or intervene in the histamine release, or cytokine release when the mast cells are de-granulated. This is a complex problem that will be solved with not just one drug but a cocktail of drugs with addition of supplements as well as prescribed drugs.

Most side effects can be dealt with histamine-receptor antagonist or different drugs that disrupt with mast-cell mediators, alongside blockers of mast-cell activation. Patients with aggressive mastocytosis may require extra drugs to interfere with the proliferation and survival of mast cells. Data is currently lacking to distinguish dependable biomarkers of mast-cell activation, signaling steps through which many triggers converge, drugs with double inhibitory activity against mast-cell proliferation and mast-cell activation, and strategies for conveying drugs particularly to mast cells. Treatment of allergic diseases depends on clinically recommended classes of drugs, for example, mast cell stabilizers and $\mathrm{H} 1$ antagonists, which control the side effects related with allergic illnesses. The mast cell stabilizer works by stabilizing the mast cell once it has been exposed to an allergen to inhibit the discharge of chemical mediators while $\mathrm{H} 1$ antagonists antagonize the histamine at the $\mathrm{H} 1$ receptor to dispose of the impacts caused by this bio-genic amine discharged amid an allergic reaction. Despite the fact that the original mast cell stabilizers, for example, DSCG and nedocromil sodium 
adequately inhibit mast cell degranulation, the second-generation mast cell stabilizers encapsulated by olopatadine and ketotifen also have anti-histaminic properties which give anti-allergic agent with dual activity.

Be that as it may, the quantity of anti-allergic agents isn't constrained to these drugs in the clinical use. Reports have shown that various compounds which have anti-allergic activity in a panel of in vitro and in vivo screens have been isolated from the natural sources. In a few circumstances, their instrument of activity isn't exclusively constrained to their impact on mast cells. Without a doubt, as a rule, they likewise target numerous inflammatory events, which may at last supplement their impact on mast cell degranulation. Additionally, a large number of these anti-allergic operators are sourced from foodstuffs, for example, the flavonoid family which enters the body every day where they could possibly target activated mast cells and lessen the mast cell response to allergens.

Various mast cell stabilizing compounds have been recognized in the most recent decade from; natural, biological and engineered sources to drugs as of now in clinical uses for different indications. Despite the fact that as a rule, the exact method of activity of these molecules is unclear, these substances have shown mast cell stabilization activity and therefore may have a potential remedial use in the treatment of allergic and related diseases where mast cells are characteristically included. In any case, owing to the heterogeneity of the mast cell, and their molecular targets, the genuine capability of any new mast cell stabilizer must be acknowledged once its properties are assessed in an extended scope of preclinical in vitro, ex vivo and in vivo models of efficacy and toxicity [61].

\section{Potential for CMT's and Polyphenols to Overcome Shortcomings}

CMTs are still in their earliest stages with respect to use in humans, for instance, the weaknesses of CMT such as the over the top suppression of MMPs which may disrupt the ordinary physiologic turnover of collagen. The question is would we be able to find the right combination or other dynamic compounds to overcome the deficiencies of CMT's. Tetracycline and its derivatives provide an advantage of MMP interaction, inhibition of MMP tissue, cytokine and growth factors.

They influence the succession of inflammation with an implication on immunomodulation, cell multiplication and angiogenesis; these activities improve their scope in treating a wide scope of disease entities. Non-antimicrobial CMTs retain their diverse activities in the organ systems. These activities include: anti-inflammatory, anti-proteolytic actions, anti-apoptotic, the inhibition of angiogenesis and tumor metastasis. A range of biological actions of CMT's in dermatitis, periodontitis, atherosclerosis, cancer, diabetes, arthritis, inflammatory bowel disease, malignancy and prevention of bone resorption as found mastocytosis is especially important to future disruptive discoveries in minocycline-like treatments, of which Quercetin is an example.

The pro-anabolic, anti-inflammatory and the anti-catabolic actions that sum 
up the non-antimicrobial characteristics of CMTs, make them a powerful pharmaceutical against chronic inflammatory disease management. The excessive inflammatory reaction to a trigger caused by an antigen in periodontitis and other chronic inflammatory disease can lead to the progression of the illness to an autoimmune disease. However, their adjunctive use in managing periodontitis and illnesses like mastocytosis could have a very beneficial effect in controlling the excessive inflammatory substance release.

\section{Conflicts of Interest}

The author declares no conflicts of interest regarding the publication of this paper.

\section{References}

[1] Ramos, B.F., Qureshi, R., Olsen, K.M. and Jakschik, B. (1990) The Importance of Mast Cells for the Neutrophil Influx in Immune Complex-Induced Peritonitis in mice. The Journal of Immunology, 145, 1868-1873.

[2] Molderings, G.J., Brettner, S., Homann, J. and Afrin, L.B. (2011) Mast Cell Activation Disease: A Concise Practical Guide for Diagnostic Workup and Therapeutic Options. Journal of Hematology and Oncology, 4, 10. https://doi.org/10.1186/1756-8722-4-10

[3] Wang, X., Ge, S., McNamara, G., Hao, Q.L., Crooks, G.M. and Nolta, J.A. (2003) Albumin-Expressing Hepatocyte-Like Cells Develop in the Livers of Immune-Deficient Mice That Received Transplants of Highly Purified Human Hematopoietic Stem Cells. Blood, 101, 4201-4208. https://doi.org/10.1182/blood-2002-05-1338

[4] Blom, B., Ho, S., Antonenko, S. and Liu, Y.-J. (2002) Generation of Interferon $\alpha$-Producing Predendritic Cell (Pre-Dc)2 from Human Cd34+ Hematopoietic Stem Cells. The Journal of Experimental Medicine, 192, 1785-1796.

[5] Murray, R.K., Bender, D.A., Botham, K.M., Kennelly, P.J., Rodwell, V.W. and Weil, P.A. (1988) Harper's Illustrated Biochemistry. 28th Edition, McGraw Hill, New York.

[6] Anand, P., Singh, B., Jaggi, A.S. and Singh, N. (2012) Mast Cells: An Expanding Pathophysiological Role from Allergy to Other Disorders. Naunyn-Schmiedeberg's Archives of Pharmacology, 385, 657-670. https://doi.org/10.1007/s00210-012-0757-8

[7] Gri, G., Frossi, B., D’Inca, F., Danelli, L., et al. (2012) Mast Cell: An Emerging Partner in Immune Interaction. Frontiers in Immunology, 3, 120. https://doi.org/10.3389/fimmu.2012.00120

[8] Lundequist, A. and Pejler, G. (2011) Biological Implications of Preformed Mast Cell Mediators. Cellular and Molecular Life Sciences, 68, 965-975. https://doi.org/10.1007/s00018-010-0587-0

[9] McNeil, H., and Austen, K.F. (1995) Biology of the Mast Cell. In: Frank, M.M., Austen, K.F., Claman, H.N. and Unanue, E.R., Eds., Samter's Immunologic Diseases, 5th editon, Little, Brown, Boston, Mass, 185-201.

[10] Bieber, T. (2004) Human Epidermal Langerhans Cells Express the High Affinity Receptor for Immunoglobulin E (Fc Epsilon RI). The Journal of Experimental Medicine, 175, 1285-1290. 
[11] Mekori, Y.A. and Metcalfe, D.D. (2000) Mast Cells in Innate Immunity. Immunological Reviews, 173, 131-140. https://doi.org/10.1034/j.1600-065X.2000.917305.x

[12] Carnahan, J. (2016) How the Immune System Controls Your Behavior. Flatiron Functional Medicine.

[13] Amin, K. (2012) The Role of Mast Cells in Allergic Inflammation. Respiratory Medicine, 106, 9-14. https://doi.org/10.1016/j.rmed.2011.09.007

[14] Keegan, A.D. and Paul, W.E. (1992) Multichain Immune Recognition Receptors: Similarities in Structure and Signaling Pathways. Immunology Today, 13, 63-68. https://doi.org/10.1016/0167-5699(92)90136-U

[15] Park, D.J., Min, H.K. and Rhee, S.G. (1991) IgE-Induced Tyrosine Phosphorylation of Phospholipase C- $\gamma 1$ in Rat Basophilic Leukemia Cells. The Journal of Biological Chemistry, 266, 24237-24240.

[16] Eiseman, E. and Bolen, J.B. (1992) Engagement of the High-Affinity IgE Receptor Activates src Protein-Related Tyrosine Kinases. Nature, 355, 78-80. https://doi.org/10.1038/355078a0

[17] Paolini, R., Jouvin, M.H. and Kinet, J.P. (1991) Phosphorylation and Dephosphorylation of the High-Affinity Receptor for Immunoglobulin E Immediately after Receptor Engagement and Disengagement. Nature, 353, 855-858. https://doi.org/10.1038/353855a0

[18] Benhamou, M. and Siraganian, R.P. (1992) Protein-Tyrosine Phosphorylation: An Essential Component of FceRl Signaling. Trends in Immunology, 6, 195-197. https://doi.org/10.1016/0167-5699(92)90152-W

[19] Clipstone, N.A. and Crabtree, G.R. (1992) Identification of Calcineurin as a Key Signalling Enzyme in T-Lymphocyte Activation. Nature, 357, 695-697. https://doi.org/10.1038/357695a0

[20] Kaye, R.E., Fruman, D.A., Bierer, B.E., Albers, M.W., et al. (2006) Effects of Cyclosporin A and FK506 on Fc Epsilon Receptor Type I-Initiated Increases in Cytokine mRNA in Mouse Bone Marrow-Derived Progenitor Mast Cells: Resistance to FK506 Is Associated with a Deficiency in FK506-Binding Protein FKBP12. Proceedings of the National Academy of Sciences of the United States of America, 89 , 8542-8546.

[21] Qureshi, R., Jakschik, B.A., Qureshi, R., Jakschik, B.A. and Jak-Schik, B.A. (1988) The Role of Mast Cells in Thioglycollate-Induced Inflammation. The Journal of Immunology, 141, 2090-2096.

[22] Zhang, Y., Ramos, B.F. and Jakschik, B.A. (1992) Neutrophil Recruitment by Tumor Necrosis Factor from Mast Cells in Immune Complex Peritonitis. Science, 258, 1957-1959. https://doi.org/10.1126/science.1470922

[23] Sylvestre, D.L. and Ravetch, J.V. (1996) A Dominant Role for Mast Cell Fc Receptors in the Arthus Reaction. Immunity, 5, 387-390. https://doi.org/10.1016/S1074-7613(00)80264-2

[24] Nettleship, E. (1869) Rare Forms of Urticaria. British Medical Journal, 2, 323-324.

[25] Ellis, J.M. (1949) Urticaria Pigmentosa; a Report of a Case with Autopsy. Archives of Pathology, 48, 426-435.

[26] Kirshenbaum, A.S., Kessler, S.W., Goff, J.P. and Metcalfe, D.D. (1991) Demonstration of the Origin of Human Mast Cells from CD34+ Bone Marrow Progenitor Cells. The Journal of Immunology, 146, 1410-1415.

[27] Ihle, J.N., Keller, J., Oroszlan, S., Henderson, L.E., et al. (1983) Biologic Properties of Homogeneous Interleukin 3. I. Demonstration of WEHI-3 Growth Factor Activ- 
ity, Mast Cell Growth Factor Activity, p Cell-Stimulating Factor Activity, Colony-Stimulating Factor Activity, and Histamine-Producing Cell-Stimulating Factor. The Journal of Immunology, 131, 282-287.

[28] Zsebo, K.M., Wypych, J., McNiece, I.K., Lu, H.S., et al. (1990) Identification, Purification, and Biological Characterization of Hematopoietic Stem Cell Factor from Buffalo Rat Liver-Conditioned Medium. Cell, 63, 195-201. https://doi.org/10.1016/0092-8674(90)90300-4

[29] Klaiber, N., Kumar, S. and Irani, A.M. (2017) Mastocytosis in Children. Current Allergy and Asthma Reports, 17, 57-63. https://doi.org/10.1007/s11882-017-0748-4

[30] Al Ghamdi, A.H., Hassan, A., Ghamdi, A., Al Ghamdi, H.S. and Al, A.A.A. (2017) Urticaria Pigmentosa in a Child with Sporadic Bilateral Diffuse Conjunctival Redness: Case Report and Review of the Literature. Case Report, 27, 192-196.

[31] Findlay, G.H., Schulz, E.J. and Pepler, W.J. (1960) Diffuse Cutaneous Mastocytosis. South African Medical Journal, 34, 353-356.

[32] Anstey, A., Lowe, D.G., Kirby, J.D. and Horton, M.A. (1991) Familial Mastocytosis: A Clinical, Immunophenotypic, Light and Electron Microscopic Study. British Journal of Dermatology, 125, 583-587. https://doi.org/10.1111/j.1365-2133.1991.tb14800.x

[33] Friedman, B.S., Steinberg, S.C., Meggs, W.J., Kaliner, M.A., Frieri, M. and Metcalfe, D.D. (1989) Analysis of Plasma Histamine Levels in Patients with Mast Cell Disorders. The American Journal of Medicine, 87, 649-654. https://doi.org/10.1016/0002-9343(89)90725-0

[34] Metcalfe, D.D. (1991) Classification and Diagnosis of Mastocytosis: Current Status. https://doi.org/10.1111/1523-1747.ep12468882

[35] Kuzin, I.I., Snyder, J.E., Ugine, G.D., Wu, D.M., et al. (2001) Tetracyclines Inhibit Activated B Cell Function. International Immunology, 13, 921-931. https://doi.org/10.1093/intimm/13.7.921

[36] Patel, R.N., Sanivarapu, S., Moogla, S. and Kapalavai, V. (1999) A Novel Mechanism of Action of Chemically Modified Tetracyclines: Inhibition of COX-2-Mediated Prostaglandin E2 Production. The Journal of Immunology, 163, 3459-3467.

[37] Golub, L.M., McNamara, T.F., D’angelo, G., Greenwald, R.A. and Ramamurthy, N.S. (1987) A Non-Antibacterial Chemically-Modified Tetracycline Inhibits Mammalian Collagenase Activity. Journal of Dental Research, 66, 1310-1314. https://doi.org/10.1177/00220345870660080401

[38] Golub, L.M., Ramamurthy, N.S., McNamara, T.F., Greenwald, R.A. and Rifkin, B.R. (1991) Tetracyclines Inhibit Connective Tissue Breakdown: New Therapeutic Implications for an Old Family of Drugs. Critical Reviews in Oral Biology and Medicine, 2, 297-321. https://doi.org/10.1177/10454411910020030201

[39] Takahashi, M., Altschmied, L. and Hillen, W. (1986) Kinetic and Equilibrium Characterization of the Tet Repressor-Tetracycline Complex by Fluorescence Measurements. Evidence for Divalent Metal Ion Requirement and Energy Transfer. Journal of Molecular Biology, 187, 341-348. https://doi.org/10.1016/0022-2836(86)90437-7

[40] Ryan, M., Usman, A., Ramamurthy, N., Golub, L. and Greenwald, R. (2012) Excessive Matrix Metalloproteinase Activity in Diabetes: Inhibition by Tetracycline Analogues with Zinc Reactivity. Current Medicinal Chemistry, 8, 305-316.

[41] Griffin, M.O., Fricovsky, E., Ceballos, G. and Villarreal, F. (2010) Tetracyclines: A Pleitropic Family of Compounds with Promising Therapeutic Properties. Review of the Literature. American Journal of Physiology_Cell Physiology, 299, C539-C548. 
https://doi.org/10.1152/ajpcell.00047.2010

[42] Fuoco, D. (2012) Classification Framework and Chemical Biology of Tetracycline-Structure-Based Drugs. Antibiotics, 1, 1-13.

https://doi.org/10.3390/antibiotics1010001

[43] Nagase, H., Enghild, J.J., Suzuki, K. and Salvesen, G. (1990) Stepwise Activation Mechanisms of the Precursor of the Matrix Metalloproteinase 3 (Stromelysin) by Proteinases and (4-Aminophenyl)mercuric Acetate. Biochemistry, 29, 5783-5789. https://doi.org/10.1021/bi00476a020

[44] Spinale, F.G. (2002) Matrix Metalloproteinases: Regulation and Dysregulation in the Failing Heart. Literature Review in Circulation Research, 90, 520-530. https://doi.org/10.1161/01.RES.0000013290.12884.A3

[45] D’Ortho, M.P., Will, H., Atkinson, S., Butler, G., Messent, A., et al. (1997) Membrane-Type Matrix Metalloproteinases 1 and 2 Exhibit Broad-Spectrum Proteolytic Capacities Comparable to Many Matrix Metalloproteinases. European Journal of Biochemistry, 250, 751-757. https://doi.org/10.1111/j.1432-1033.1997.00751.x

[46] Rohde, L.E., Ducharme, A., Arroyo, L.H., Aikawa, M., et al. (1999) Matrix Metalloproteinase Inhibition Attenuates Early Left Ventricular Enlargement after Experimental Myocardial Infarction in Mice. Circulation, 99, 3063-3070. https://doi.org/10.1161/01.CIR.99.23.3063

[47] Park, J.L. and Lucchesi, B.R. (1999) Mechanisms of Myocardial Reperfusion Injury. Annals of Thoracic Surgery, 68, 1905-1912. https://doi.org/10.1016/S0003-4975(99)01073-5

[48] Kraus, R.L., Pasieczny, R., Lariosa-Willingham, K., Turner, M.S., Jiang, A. and Trauger, J.W. (2005) Antioxidant Properties of Minocycline: Neuroprotection in an Oxidative Stress Assay and Direct Radical-Scavenging Activity. Journal of Neurochemistry, 94, 819-827. https://doi.org/10.1111/j.1471-4159.2005.03219.x

[49] Onoda, T., Ono, T., Dhar, D.K., Yamanoi, A., Fujii, T. and Nagasue, N. (2004) Doxycycline Inhibits Cell Proliferation and Invasive Potential: Combination Therapy with Cyclooxygenase-2 Inhibitor in Human Colorectal Cancer Cells. Journal of Laboratory and Clinical Medicine, 143, 207-216. https://doi.org/10.1016/j.lab.2003.12.012

[50] Lokeshwar, B.L., Selzer, M.G., Zhu, B.Q., Block, N.L. and Golub, L.M. (2002) Inhibition of Cell Proliferation, Invasion, Tumor Growth and Metastasis by an Oral Non-Antimicrobial Tetracycline Analog (COL-3) in a Metastatic Prostate Cancer Model. International Journal of Cancer, 98, 297-309. https://doi.org/10.1002/ijc.10168

[51] Pourgholami, M.H., Ataie-Kachoie, P., Badar, S. and Morris, D.L. (2013) Minocycline Inhibits Malignant Ascites of Ovarian Cancer through Targeting Multiple Signaling Pathways. Gynecologic Oncology, 129, 113-119. https://doi.org/10.1016/j.ygyno.2012.12.031

[52] Tolomeo, M., Grimaudo, S., Milano, S., La Rosa, M., Ferlazzo, V., et al. (2001) Effects of Chemically Modified Tetracyclines (CMTs) in Sensitive, Multidrug Resistant and Apoptosis Resistant Leukaemia Cell Lines. British Journal of Pharmacology, 133, 306-314. https://doi.org/10.1038/sj.bjp.0704068

[53] Seftor, R.E.B., Seftor, E.A., De Larco, J.E., Kleiner, D.E., Leferson, J., et al. (1998) Chemically Modified Tetracyclines Inhibit Human Melanoma Cell Invasion and Metastasis. Clinical \& Experimental Metastasis, 16, 217-225.

[54] Selzer, M.G., Zhu, B., Block, N.L. and Lokeshwar, B.L. (1999) CMT-3, a Chemically 
Modified Tetracycline, Inhibits Pony Metastases and Delays the Development of Paraplegia in a Rat Model of Prostate Cancer. Annals of the New York Academy of Sciences, 878, 678-682. https://doi.org/10.1111/j.1749-6632.1999.tb07760.x

[55] Lokeshwar, B.L. (1999) MMP Inhibition in Prostate Cancer. Annals of the New York Academy of Sciences, 878, 271-289.

[56] van den Bogert, C., Dontje, B.H.J. and Kroon, A.M. (1985) The Antitumour Effect of Doxycycline on a T-Cell Leukaemia in the Rat. Leukemia Research, 9, 617-623. https://doi.org/10.1016/0145-2126(85)90142-0

[57] Onoda, T., Ono, T., Dhar, D.K., Yamanoi, A. and Nagasue, N. (2006) Tetracycline Analogues (Doxycycline and COL-3) Induce Caspase-Dependent and -Independent Apoptosis in Human Colon Cancer Cells. International Journal of Cancer, 118, 1309-1315. https://doi.org/10.1002/ijc.21447

[58] Quideau, S., Deffieux, D., Douat-Casassus, C. and Pouységu, L. (2011) Plant Polyphenols: Chemical Properties, Biological Activities, and Synthesis. Angewandte Chemie-International Edition, 50, 586-621. https://doi.org/10.1002/chin.201117261

[59] Nonaka, G. (2007) Isolation and Structure Elucidation of Tannins. Pure and Applied Chemistry, 61, 357-360. https://doi.org/10.1351/pac198961030357

[60] Piccolella, S. and Pacifico, S. (2015) Plant-Derived Polyphenols: A Chemopreventive and Chemoprotectant Worth-Exploring Resource in Toxicology. Advances in Molecular Toxicology, 9, 161-214. https://doi.org/10.1016/B978-0-12-802229-0.00005-0

[61] Finn, D.F. and Walsh, J.J. (2013) Twenty-First Century Mast Cell Stabilizers. British Journal of Pharmacology, 170, 23-37. https://doi.org/10.1111/bph.12138

[62] Lee, J., Jung, E., Park, J., Jung, K., et al. (2005) Anti-Inflammatory Effects of Magnolol and Honokiol Are Mediated through Inhibition of the Downstream Pathway of MEKK-1 in NF- $\kappa$ B Activation Signaling. Planta Medica, 71, 338-343. https://doi.org/10.1055/s-2005-864100

[63] Kang, O.H., Jang, H.-J., Chae, H.-S., Oh, Y.-C., et al. (2009) Anti-Inflammatory Mechanisms of Resveratrol in Activated HMC-1 Cells: Pivotal Roles of NF- $\kappa \mathrm{B}$ and MAPK. Pharmacological Research, 59, 330-337. https://doi.org/10.1016/j.phrs.2009.01.009

[64] El-Agamy, D.S. (2012) Anti-Allergic Effects of Nilotinib on Mast Cell-Mediated Anaphylaxis like Reactions. European Journal of Pharmacology, 680, 115-121. https://doi.org/10.1016/j.ejphar.2012.01.039

[65] Lee, J.H., Kim, J.W., Ko, N.Y., Mun, S.H., et al. (2008) Curcumin, a Constituent of Curry, Suppresses IgE-Mediated Allergic Response and Mast Cell Activation at the Level of Syk. Journal of Allergy and Clinical Immunology, 121, 1225-1231. https://doi.org/10.1016/j.jaci.2007.12.1160

[66] Wendt, K.S., Yoshida, K., Itoh, T., Bando, M., et al. (2008) Cohesin Mediates Transcriptional Insulation by CCCTC-Binding Factor. Nature, 451, 796-801. https://doi.org/10.1038/nature06634

[67] Van De Ven, A.H. and Poole, M.S. (1995) Explaining Development and Change in Organizations. Academy of Management Review, 20, 510-540. https://doi.org/10.2307/258786

[68] Dyer, J., Gregersen, H. and Christensen, C.M. (2011) The Innovator's DNA: Mastering the Five Skills of Disruptive Innovators. Harvard Business Review Press, Boston.

[69] D’Agostino, P., Ferlazzo, V., Milano, S., La Rosa, M., Di Bella, G., et al. (2003) 
Chemically Modified Tetracyclines Induce Cytotoxic Effects against J774 Tumour Cell Line by Activating the Apoptotic Pathway. International Immunopharmacology, 3, 63-73. https://doi.org/10.1016/S1567-5769(02)00213-8

[70] Alevizos, M., Karagkouni, A., Vasiadi, M., Sismanopoulos, N., et al. (2013) Rupatadine Inhibits Inflammatory Mediator Release from Human Laboratory of Allergic Diseases 2 Cultured Mast Cells Stimulated by Platelet-Activating Factor. Annals of Allergy, Asthma \& Immunology, 111, 542-547. https://doi.org/10.1016/j.anai.2013.08.025

[71] Butterfield, J.H. (2010) Increased Leukotriene E4 Excretion in Systemic Mastocytosis. Prostaglandins \& Other Lipid Mediators, 92, 73-76. https://doi.org/10.1016/j.jaci.2009.12.707

[72] Clemons, A., Vasiadi, M., Kempuraj, D., Kourelis, T., Vandoros, G. and Theoharides, T.C. (2011) Amitriptyline and Prochlorperazine Inhibit Proinflammatory Mediator Release from Human Mast Cells: Possible Relevance to Chronic Fatigue Syndrome. Journal of Clinical Psychopharmacology, 31, 385-387. https://doi.org/10.1097/JCP.0b013e3182196e50

[73] Godt, O., Proksch, E., Streit, V. and Christophers, E. (1997) Short- and Long-Term Effectiveness of Oral and Bath PUVA Therapy in Urticaria Pigmentosa and Systemic Mastocytosis. Dermatology, 195, 35-39. https://doi.org/10.1159/000245681 